\title{
Prevalência e perfil de resistência de bactérias isoladas em uroculturas de pacientes de uma cidade do interior do Rio Grande do Sul
}

\author{
Prevalence and resistance profile of bacterial isolated in urine cultures of patients \\ from a city in the interior of Rio Grande do Sul
}

\author{
Grasiela Saltona, Mônica Jachetti Maciel ${ }^{b}$ \\ a Biomédica. Universidade do Vale do Taquari (Univates), Centro de Ciências Biológicas e da Saúde (CCBS). \\ b Bióloga. Doutora em Ciências Veterinárias. Docente e Pesquisadora da Universidade do Vale do Taquari (Univates), CCBS, Programa de Pós-Graduação em \\ Sistemas Ambientais Sustentáveis (PPGSAS). \\ Fonte de financiamento: Universidade do Vale do Taquari (Univates).
}

\begin{tabular}{l|l} 
RESUMO Objetivos: Este estudo objetivou verificar a prevalência e o perfil de resistência de bactérias isoladas em uroculturas &
\end{tabular} frente aos antibióticos comumente utilizados em pacientes ambulatoriais da comunidade.

Materiais e Métodos: Foi realizado um estudo retrospectivo documental com abordagem quantitativa com base na análise de 55 prontuários de exames realizados durante os meses de junho 2014 a junho 2016, em uma cidade do interior do Rio Grande do Sul, Brasil.

Resultados: A partir dos 616 prontuários, foram identificados 55 (9\%) dos casos como bacteriúria significativa. O principal patógeno presente nas uroculturas foi Escherichia coli com 70\% (38), seguido por Staphylococcus aureus com 21\% (12) e Enterobacter spp., com 9\% (5). Pacientes do sexo feminino foram os mais acometidos representando $87 \%$ (48) dos casos. Em relação à faixa etária houve maior prevalência de bacteriúria significativa entre os indivíduos que apresentaram idade entre 61 a 80 anos, 40\% (22). Sobre os perfis de resistência, 29\% de E. coli apresentaram resistência a sulfametoxazol-trimetropima, $17 \%$ de $S$. aureus apresentaram resistência aos antimicrobianos nitrofurantoína e sulfametoxazol-trimetropima e 40\% de Enterobacter spp., apresentaram índice de resistência à clindamicina.

Conclusão: Os dados permitem concluir que no presente estudo houve alta prevalência de bacteriúria significativa em mulheres, assim como em uma faixa etária de 61 a 80 anos. O principal patógeno encontrado foi E. coli, seguido por S. aureus e Enterobacter spp. Em relação aos antibióticos, observa-se alto índice de resistência de Enterobacter spp., seguida por E. coli e $S$. aureus.

Palavras chave: agentes antibacterianos; bacteriúria; prevalência; antibióticos. 


\section{INTRODUÇÃO}

A infecção do trato urinário (ITU) é considerada como a segunda infecção bacteriana mais comum em seres humanos e uma das principais razões para a prescrição de antimicrobianos. Caracterizada pela invasão e multiplicação bacteriana nos tecidos do trato urinário, pode acometer a uretra e chegar até os rins causando uma bacteriúria sintomática ou assintomática'.

A ITU pode afetar um único local, tal como os rins (pielonefrite), bexiga (cistite), próstata (prostatite) ou uretra

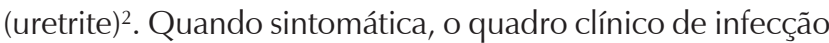
urinária pode ser bastante sugestivo para o diagnóstico, incluindo dor lombar e/ou suprapúbica, disúria, polaciúria, urgência miccional, nictúria, urina turva (pela presença de piúria) e/ou avermelhada (pela hematúria), febre e calafrios (na pielonefrite), no entanto o diagnóstico só é confirmado pela urocultura, primordial dentro da clínica médica ${ }^{3}$.

No Brasil, 80 em cada 1.000 consultas clínicas estão relacionadas às infecções do trato urinário, de origem bacteriana ${ }^{4}$. A infecção urinária nos Estados Unidos representa 7 milhões de consultas médicas por ano e são responsáveis por 1 milhão de internações hospitalares ${ }^{5}$.

A ITU acomete ambos os sexos de variadas idades, porém os mais frequentes são, mulheres jovens sexualmente ativas, idosos de ambos os sexos e homens com obstrução prostática que dificulta o esvaziamento vesical completo, favorecendo o crescimento bacteriano ${ }^{6}$. Em adultos a incidência é maior em mulheres devido ao fato de a uretra feminina ser mais curta do que a dos homens, sendo assim a proximidade do ânus com a vagina é maior. Em idosos após os 60 anos de idade há um aumento de casos de ITU atingindo de 3 a $4 \%$ dos homens, casos que estão correlacionados com o desenvolvimento de hiperplasia prostática. Em mulheres nesta mesma faixa etária o possível fator associado ao desenvolvimento de infecções está relacionado à deficiência de estrogênio (menopausa) e condições precárias de higiene? Aproximadamente $50 \%$ a $70 \%$ das mulheres apresentam casos de ITUs pelo menos uma vez durante a vida, em 20 a $30 \%$ delas ocorrem episódios recorrentes ${ }^{8}$.

Micro-organismos isolados de infecções urinárias adquiridas em hospitais apresentam uma maior resistência aos agentes antimicrobianos. A maioria dos estudos publicados referem-se ao perfil de resistência de isolados nas infecções nosocomiais (hospitalares). Entretanto, cepas bacterianas multirresistentes também podem ser isoladas em pacientes da comunidade ${ }^{8}$.

De todas as infecções hospitalares, cerca de 35 a $45 \%$ delas são responsáveis por infecções urinárias adquiridas no hospital. A infecção urinária adquirida na comunidade está entre as infecções mais comuns, com maior frequência em mulheres. Fatores como gravidez, início de atividade sexual e menopausa contribuem para o alto índice de ocorrência no sexo feminino durante a vida toda 9 .

A maioria das ITUs são provenientes da flora intestinal e são causadas por bactérias Gram-negativas, sendo o patógeno mais comum Escherichia coli correspondendo a 70 a $90 \%$ dos casos adquiridos fora de hospitais. Nas infecções hospitalares essa frequência diminui para 50 a $60 \%$ permanecendo mesmo assim como o principal agente etiológico ${ }^{10}$.

Nas infecções comunitárias os achados mais comuns são bactérias aeróbicas Gram-negativas (E. coli, Proteus mirabilis, Enterobacter spp., Serratia spp., Klebsiella spp., Morganella morganii, Pseudomonas aeruginosa), cocos Gram-positivos (Streptococcus grupo B e D, Staphylococcus saprophyticus) e alguns anaeróbios (Bacteroides fragilis) ${ }^{11}$.

A resistência bacteriana é uma preocupação mundial. No Brasil o uso indiscriminado de antibióticos, fez com que a Organização Mundial da Saúde (OMS) indicasse a restrição do seu uso. A Agência Nacional de Vigilância Sanitária (ANVISA) estabeleceu por meio da Resolução (RDC) no 20, de 05 de maio de 2011, a obrigatoriedade de apresentação de receita médica na venda deste tipo de medicamento contendo em anexo a lista de 119 antimicrobianos registrados. A receita médica passou a ser retida e apresentar data de validade para impedir a venda do antibiótico após o prazo. Em dezembro de 2014 esse número passou para 128 substâncias sujeitas à retenção de receita ${ }^{12}$.

Diante da falha de tratamento eficaz na ITU, há uma grande preocupação com o conhecimento epidemiológico das mesmas e do padrão de sensibilidade e resistência dos agentes causais. A prevalência de resistência bacteriana aos antibióticos nas infecções comunitárias vem crescendo nos últimos anos, mas ainda há poucos trabalhos nesta área ${ }^{4}$. A fim de atualizar informações sobre os agentes envolvidos em ITU, o presente trabalho teve como objetivo identificar os principais patógenos isolados em urocultura de pacientes ambulatoriais da comunidade e verificar a prevalência e o perfil de resistência bacteriana frente aos antibióticos comumente utilizados em pacientes da comunidade.

\section{MATERIAIS E MÉTODOS}

Foi realizada uma pesquisa retrospectiva documental com abordagem quantitativa com base em prontuários de pacientes ambulatoriais que realizaram uroculturas com o teste de sensibilidade a antimicrobianos (TSA) em um laboratório de análises clínicas particular localizado no interior do Rio Grande do Sul. Os prontuários analisados datavam o período compreendido entre os meses de junho 
de 2014 a junho de 2016. A consulta ao banco de dados ocorreu entre os meses de março e junho de 2016. A autorização para acesso a todos os registros de uroculturas e antibiogramas neste período foi concedida pelo responsável técnico (RT) do laboratório.

Foram utilizados os seguintes critérios de inclusão: análise de registros de prontuários de exames feitos de todas as uroculturas realizadas no período de estudo através do teste de sensibilidade a antimicrobianos (TSA); foram consideradas uroculturas indicativas de bacteriúria significativa àquelas que apresentaram contagens iguais ou maiores a $10^{5} \mathrm{UFC} / \mathrm{mL}$ (Unidades Formadoras de Colônia por mililitro de urina) e a análise realizada com a primeira urina da manhã; faixa etária compreendida entre 0 a 100 anos de idade de ambos os sexos. Como critérios de exclusão se considerou os exames em duplicata, ou seja, aqueles exames do mesmo paciente, o agente etiológico e o perfil de resistência em um período de quatro meses e pacientes de outros municípios.

Este trabalho foi realizado mediante aprovação do Comitê de Ética e Pesquisa envolvendo seres humanos da Univates (COEP-Univates) sob número 1.432.136 atendendo os preceitos éticos na Resolução no 466/2012, do Ministério da Saúde $(M S)^{13}$.

Os resultados observados foram avaliados em planilha Excel e apresentados em percentual (\%) e número absoluto.

\section{RESULTADOS}

Inicialmente existiam 616 prontuários de pacientes que realizaram exames de urocultura. Destes, apenas 99 (16\%) apresentaram-se positivos para bacteriúria significativa e 517 (84\%) negativos. Assim, foram excluídos 52 (8\%) prontuários devido aos critérios de exclusão adotados como infecção recorrente (28-4,54\%), amostras sem informações necessárias (09-1,46\%), e pacientes de outros municípios (15-2,44\%). Desse modo, permaneceram 55 (9\%) amostras positivas de pacientes com bacteriúria significativa.

Dos 55 prontuários de pacientes avaliados, em relação a variável sexo, foi encontrada predominância no gênero feminino com 48 (87\%) dos casos, enquanto que o sexo masculino apresentou 07 (13\%). Foi observada maior prevalência de bacteriúria significativa entre idosos na faixa etária de 61 a 80 anos (Tabela 1), representando 40\% (22), sendo que destes, $77 \%$ (17) eram mulheres e $23 \%$ (5), homens. Para a faixa etária de 0 a 15 anos de idade foi encontrada prevalência no sexo feminino, sendo 04 (80\%) e $01(20 \%)$ no sexo masculino.

O patógeno mais frequente isolado foi $E$. coli representando $70 \%$ (38) do total de bactérias isoladas. A segunda bactéria mais prevalente foi $S$. aureus, que correspondeu a 21\% (12), seguida pelo gênero Enterobacter spp., com 9\% (05) (Figura 1).
Os perfis de resistência bacteriana frente aos antimicrobianos nas infecções de origem comunitária estão apresentados na Tabela 2. Observa-se a significativa resistência de $E$. coli para sulfametoxazol-trimetropima (29\%) e nitrofurantoína (16\%).

Tabela 1. Distribuição dos casos de bacteriúria significativa por gênero de acordo com a faixa etária, em números absolutos (n) e em porcentagem (\%).

\begin{tabular}{cccc}
\hline Faixa etária & $\begin{array}{c}\text { Homens } \\
\mathbf{n}(\%)\end{array}$ & $\begin{array}{c}\text { Mulheres } \\
\mathbf{n}(\%)\end{array}$ & $\begin{array}{c}\text { Total } \\
\mathbf{n}(\%)\end{array}$ \\
\hline $0-15$ & $1(20)$ & $4(80)$ & $5(9)$ \\
$16-40$ & $1(7)$ & $14(93)$ & $15(27)$ \\
$41-60$ & $0(0)$ & $9(100)$ & $9(17)$ \\
$61-80$ & $5(23)$ & $17(77)$ & $22(40)$ \\
$81-100$ & $0(0)$ & $4(100)$ & $4(7)$ \\
Total & $7(13)$ & $48(87)$ & $55(100)$ \\
\hline
\end{tabular}

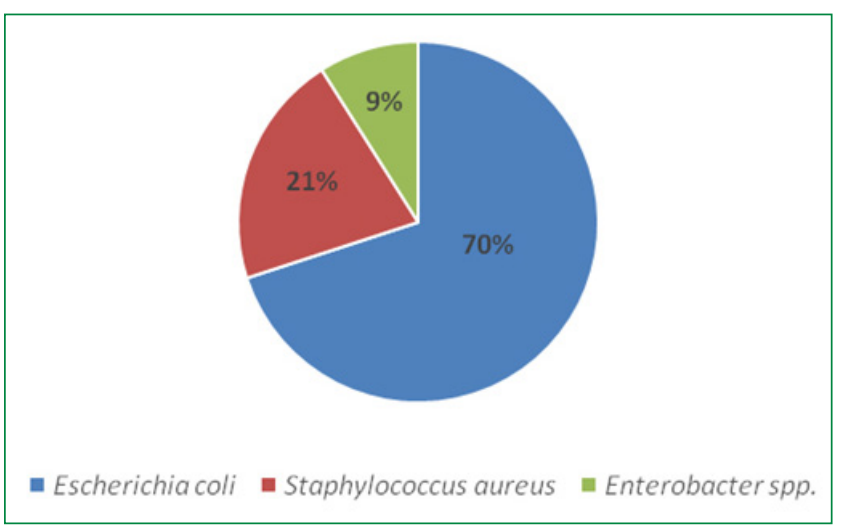

Figura 1. Prevalência (\%) dos micro-organismos isolados em uroculturas realizadas por qualquer causa.

Em relação ao S. aureus 17\% apresentaram resistência aos antimicrobianos nitrofurantoína e sulfametoxazoltrimetropima. Cerca de $8 \%$ de S. aureus apresentaram resistência aos antimicrobianos: ácido pipemídico, ácido nalidíxico, clindamicina, tetraciclina e vancomicina (Tabela 2). A análise do perfil de resistência revelou que, apesar de menos prevalente, as amostras de Enterobacter spp., apresentaram um alto índice de resistência à clindamicina $(60 \%)$, eritromicina, vancomicina, penicilina e oxacilina $(40 \%)$ e outras apresentaram $20 \%$ de resistência.

Na Tabela 3 estão apresentados os dados de microorganismos multirresistentes. Seis E. coli $(16 \%)$ e duas Enterobacter spp. (40\%) foram multirresistentes, ou seja, apresentaram resistência a três ou mais grupos de agentes antimicrobianos. 
Tabela 2. Perfil de resistência bacteriana frente aos antimicrobianos em números absolutos (n) e em porcentagem (\%).

\begin{tabular}{|c|c|c|c|}
\hline Grupos Químicos & $\begin{array}{l}\text { E. coli } \\
\text { n (\%) }\end{array}$ & $\begin{array}{c}\text { S. aureus } \\
\text { n (\%) }\end{array}$ & $\begin{array}{c}\text { Enterobacter spp. } \\
\text { n (\%) }\end{array}$ \\
\hline \multicolumn{4}{|l|}{ Quinolona } \\
\hline Ácido Pipemídico & $0(0)$ & $1(8)$ & $0(0)$ \\
\hline Ácido Nalidíxico & $1(3)$ & $1(8)$ & $1(20)$ \\
\hline \multicolumn{4}{|l|}{ Fluorquinolonas } \\
\hline Ciprofloxacina & $1(3)$ & $0(0)$ & $0(0)$ \\
\hline Norfloxacina & $2(5)$ & $0(0)$ & $0(0)$ \\
\hline \multicolumn{4}{|l|}{ Penicilinas } \\
\hline Ampicilina & $4(11)$ & $0(0)$ & $1(20)$ \\
\hline Amoxicilina + clavulanato & $0(0)$ & $0(0)$ & $1(20)$ \\
\hline Oxacilina & $2(5)$ & $0(0)$ & $2(40)$ \\
\hline Penicilina & $1(3)$ & $0(0)$ & $2(40)$ \\
\hline Carbenicilina & $3(8)$ & $0(0)$ & $0(0)$ \\
\hline \multicolumn{4}{|l|}{ Cefalosporinas } \\
\hline Cefalotina (1a geração) & $0(0)$ & $0(0)$ & $1(20)$ \\
\hline Cefoxitina ( $2^{\mathrm{a}}$ geração) & $1(3)$ & $0(0)$ & $1(20)$ \\
\hline \multicolumn{4}{|l|}{ Macrolídeos } \\
\hline Eritromicina & $1(3)$ & $0(0)$ & $2(40)$ \\
\hline \multicolumn{4}{|l|}{ Aminoglicosídeos } \\
\hline Netilmicina & $1(3)$ & $0(0)$ & $0(0)$ \\
\hline Tobramicina & $2(5)$ & $0(0)$ & $0(0)$ \\
\hline \multicolumn{4}{|l|}{ Sulfonamidas } \\
\hline Sulfametoxazol + Trimetropima & $11(29)$ & $2(17)$ & $1(20)$ \\
\hline \multicolumn{4}{|l|}{ Tetraciclinas } \\
\hline Tetraciclina & $3(8)$ & $1(8)$ & $0(0)$ \\
\hline \multicolumn{4}{|l|}{ Glicopeptídeos } \\
\hline Vancomicina & $2(5)$ & $1(8)$ & $2(40)$ \\
\hline \multicolumn{4}{|l|}{ Outros } \\
\hline Cloranfenicol & $1(3)$ & $0(0)$ & $1(20)$ \\
\hline Clindamicina & $2(5)$ & $1(8)$ & $3(60)$ \\
\hline Rifampicina & $0(0)$ & $0(0)$ & $1(20)$ \\
\hline Nitrofurantoina & $6(16)$ & $2(17)$ & $1(20)$ \\
\hline
\end{tabular}

\section{DISCUSSÃO}

A prevalência de uroculturas positivas (16\%) nesta pesquisa é semelhante ao encontrado por Poletto \& Reis ${ }^{14}$, na cidade de Goiânia (GO), que obtiveram $17,6 \%$ das amostras positivas para uropatógenos ${ }^{14}$. Segundo Muller et al. ${ }^{15}$, em estudo feito no sul do Brasil, em UmuaramaPR, evidenciaram 15,85\% dos prontuários analisados com resultados positivos para ITU ${ }^{15}$.

De acordo com Correa et al. ${ }^{7}$, o sexo feminino possui condições anatômicas favoráveis para o desenvolvimento de ITU, como os fatores fisiológicos, por exemplo. Se comparada ao sexo masculino, o feminino possui a uretra mais curta e mais próxima às áreas colonizadas por diversos micro-organismos, como a região perianal e vulvar.

O resultado encontrado neste estudo quanto à predominância do gênero feminino (87\%) foi semelhante com
Tabela 3. Multirresistência de E. coli e Enterobacter spp., frente aos antimicrobianos.

\begin{tabular}{|c|c|c|c|c|c|c|c|c|}
\hline \multirow{2}{*}{ *ATM/CEPAS } & \multicolumn{6}{|c|}{ E. coli } & \multicolumn{2}{|c|}{ Ent. } \\
\hline & 01 & 02 & 03 & 04 & 05 & 06 & 01 & 02 \\
\hline \multicolumn{9}{|l|}{ Quinolonas } \\
\hline Ácido Nalidíxico & & $\mathrm{R}$ & & & & & & $\mathrm{R}$ \\
\hline \multicolumn{9}{|l|}{ Fluorquinolona } \\
\hline Norfloxacina & & & & $\mathrm{R}$ & & & & \\
\hline \multicolumn{9}{|l|}{ Penicilinas } \\
\hline Ampicilina & & $\mathrm{R}$ & $\mathrm{R}$ & & & & & $\mathrm{R}$ \\
\hline *AMC & & & & & & & & $\mathrm{R}$ \\
\hline Oxacilina & $\mathrm{R}$ & $\mathrm{R}$ & & & & & & $\mathrm{R}$ \\
\hline Penicilina & & $\mathrm{R}$ & & & & & & $\mathrm{R}$ \\
\hline Carbenicilina & & & & $\mathrm{R}$ & $\mathrm{R}$ & & & \\
\hline \multicolumn{9}{|l|}{ Cefalosporinas } \\
\hline Cefalotina (1a geração) & & & & & & & & $\mathrm{R}$ \\
\hline Cefoxitina ( $2^{\mathrm{a}}$ geração) & & & & & $\mathrm{R}$ & & & \\
\hline \multicolumn{9}{|l|}{ Macrolídeos } \\
\hline Eritromicina & & $\mathrm{R}$ & & & & $\mathrm{R}$ & $\mathrm{R}$ & \\
\hline \multicolumn{9}{|l|}{ Aminoglicosídeos } \\
\hline Netilmicina & & & & $\mathrm{R}$ & & & & \\
\hline Tobramicina & & & & $\mathrm{R}$ & & & & \\
\hline \multicolumn{9}{|l|}{ Sulfonamidas } \\
\hline *SFT & & $\mathrm{R}$ & $\mathrm{R}$ & $\mathrm{R}$ & $\mathrm{R}$ & & & $\mathrm{R}$ \\
\hline \multicolumn{9}{|l|}{ Tetraciclinas } \\
\hline Tetraciclina & & $\mathrm{R}$ & & & & & & \\
\hline \multicolumn{9}{|l|}{ Glicopeptídeos } \\
\hline Vancomicina & $\mathrm{R}$ & & & $\mathrm{R}$ & & & & $\mathrm{R}$ \\
\hline \multicolumn{9}{|l|}{ Outros } \\
\hline Cloranfenicol & & & $\mathrm{R}$ & & & & & $\mathrm{R}$ \\
\hline Clindamicina & $\mathrm{R}$ & $\mathrm{R}$ & & & & $\mathrm{R}$ & $\mathrm{R}$ & $\mathrm{R}$ \\
\hline Rifampicina & & & & & & $\mathrm{R}$ & $\mathrm{R}$ & \\
\hline Nitrofurantoina & & & & $\mathrm{R}$ & $\mathrm{R}$ & & & $\mathrm{R}$ \\
\hline
\end{tabular}

*Ent.: Enterobacter spp.; *ATM: Antimicrobianos; *AMC: Amoxicilina + clavulanato; *SFT: Sulfametoxazol-trimetropima.

a pesquisa de Rodrigues et al. ${ }^{6}$, que analisaram o perfil epidemiológico das infecções urinárias em Natal (RN), cuja prevalência foi maior no sexo feminino (135 pacientes- 85\%), quando comparado ao sexo masculino (15\%) de uroculturas positivas para ITU ${ }^{6}$. Um estudo realizado em Portugal por Rodrigues \& Barroso ${ }^{16}, 84 \%$ dos exames apresentaram resultados positivos para indivíduos do sexo feminino e $16 \%$ para indivíduos do sexo masculino ${ }^{16}$, corroborando com os achados desta pesquisa.

Na mulher idosa, as causas de prevalência de ITU são múltiplas, a menopausa e as consequentes mudanças hormonais, ocasionam alteração do $\mathrm{pH}$ e da flora locais, constituindo, assim, um grande fator de risco para ITU ${ }^{16}$. Os idosos do sexo masculino são acometidos por esta infecção possivelmente devido ao aumento prostático nesta fase, dificultando o esvaziamento vesical ${ }^{17}$. O resultado do estudo de Zimmermann et al. ${ }^{18}$ foi condizente com os 
observados nesta pesquisa, pois cerca de $45,68 \%$ dos idosos apresentaram resultados positivos de ITU, nesta mesma faixa etária ${ }^{18}$. A terceira idade favorece o desenvolvimento de ITU, devido às alterações funcionais e orgânicas do trato geniturinário, imobilidade, imunodeficiência relacionada à idade e a presença de doenças sistêmicas ${ }^{6}$.

O resultado da prevalência feminina (77\%) na faixa etária de 0 a 15 anos de idade foi semelhante a pesquisa desenvolvida por Lo et al. ${ }^{19}$, sobre infecção urinária em menores de 15 anos no pronto atendimento de pediatria do Hospital Universitário da Universidade de São Paulo. O estudo de Lo et al. ${ }^{19}$ apresentou predomínio no sexo feminino em 133 (76\%) dos casos e em 43 (24\%) do sexo masculino, para esta mesma faixa etária.

Conforme o estudo publicado por Soares et al. ${ }^{20}$, a bactéria mais prevalente foi $E$. coli, representando $63,64 \%$ das amostras positivas seguida por $S$. aureus com $18,18 \%{ }^{20}$. Dados publicados por outros autores em diferentes regiões do Brasil também apresentaram E. coli como patógeno mais prevalente, como os estudos feitos por Poletto \& Reis ${ }^{14}$, em Goiânia (GO), com 67,9\%, por Braoios et al. ${ }^{8}$, em São Paulo (SP) 65,97\%, e por Pires et al. ${ }^{3}$, em Brasília (DF) 62,4\%. Estes resultados estavam próximos aos encontrados neste trabalho. Assim como os demais estudos citados anteriormente, a pesquisa de Hinrichsen et al. ${ }^{21}$, o patógeno mais comum encontrado foi $E$. coli proveniente de $70 \%$ a $95 \%$ dos casos de infecção urinária adquirida na comunidade, corroborando com achados neste estudo em relação a prevalência ${ }^{21}$.

A prevalência encontrada de $S$. aureus $(21 \%)$, neste estudo, possivelmente se dá devido ao fato de ser uma bactéria facilmente encontrada na pele e nas fossas nasais podendo colonizar região perineal e trato urinário. Acomete principalmente pessoas que estão com a imunidade comprometida por outras patologias ou condições fisiológicas como a idade ${ }^{22}$.

Um estudo feito por Massoli et al. ${ }^{23}$, demonstrou que o grupo das enterobactérias foi o mais predominante com $83 \%$ dos casos, sendo $E$. coli presente em $75 \%$ das infecções, seguida pelo gênero Enterobacter spp. (11\%), Klebsiella pneumoniae (7\%), Proteus mirabilis (5,6\%) e Klebsiella oxytoca $(1,4 \%)$. Entre os cocos Gram-positivos (17\%), Staphylococcus saprophyticus e Staphylococcus sp. foram os mais frequentes, representando 36\%, seguido por Streptococcus spp. (14\%), S. aureus e Streptococcus grupo D, com $7 \%{ }^{23}$.

A resistência de E.coli à sulfametoxazol-trimetropima (29\%) também foi relatado por Massoli et al. ${ }^{23}$, em uma pesquisa realizada em pacientes do Sistema Único de Saúde (SUS), esta bactéria foi a principal responsável por infecções do trato urinário observando uma resistência de 39\% dos isolados frente a sulfametoxazol-trimetropima ${ }^{23}$.
Um estudo realizado no Brasil, no tratamento das ITUs, evidenciou alto índice de resistência de $E$. coli frente a amoxicilina/ampicilina, sulfametoxazol-trimetropima e cefalotina, sendo que os antibióticos mais administrados para o tratamento empírico desta infecção, adquirida na comunidade em adultos são quinolonas (norfloxacina ou ciprofloxacina), sulfametoxazol-trimetropima, cefalosporinas de primeira ou segunda geração, amoxicilina-clavulanato ou nitrofurantoína. No entanto, a crescente resistência antimicrobiana deixa dúvidas quanto à validade destes tratamentos ${ }^{24}$.

Nos últimos anos observou-se um aumento significativo na resistência a diversos antimicrobianos. Os grupos que mais se destacam são os betalactâmicos e quinolonas. Os patógenos têm apresentado maior resistência frente a esses grupos de fármacos, predominantemente em pacientes hospitalizados se comparados aos pacientes ambulatoriais. Pesquisadores da Holanda observaram um aumento na resistência frente a amoxacilina e sulfametoxazol-trimetropima em isolados de E. coli. Com o passar dos anos, começaram a ser prescritas frequentemente, fluoroquinolonas para infecções do trato urinário, ocasionando um aumento na resistência de $E$. coli frente a fluoroquinolonas ${ }^{25}$.

O relatório da $\mathrm{OMS}^{26}$ revelou que existe uma preocupação mundial acerca da resistência microbiana frente aos antibióticos, pois esse problema afeta hospitais em todo o mundo, dificultado a capacidade de tratar infecções comuns. A humanidade está caminhando para uma era pósantibiótica, cujas infecções comuns e pequenas lesões que eram tratadas com sucesso durante décadas, agora podem ser fatais. O documento reforça que existe a necessidade de se ter ações urgentes para o controle desta resistência.

A expressão "multirresistência" pode ser empregada quando um micro-organismo apresentar resistência a três ou mais grupos de agentes antimicrobianos ${ }^{27}$, foi o que ocorreu com $16 \%$ de E. coli (6) e 40\% de Enterobacter spp (2). Nos últimos anos há uma crescente prevalência da resistência aos fármacos antimicrobianos nas infecções comunitárias, mas ainda existem poucos trabalhos referindo-se a este tema, ao contrário das infecções nosocomiais. O crescente aumento das bactérias resistentes aos múltiplos fármacos antimicrobianos representa um desafio no tratamento destas infecções, resultando na grande importância e necessidade de revisões e análises nesta questão ${ }^{3}$.

A infecção do trato urinário é uma das doenças mais frequentes, afetando milhares de pessoas todo ano, com consequências graves, sendo sua prevenção muito importante. Esta pesquisa constatou que Escherichia coli foi a bactéria mais isolada nas bacteriúrias significativas em pacientes ambulatoriais da comunidade, seguida de Staphylococcus aureus e Enterobacter spp. Também ficou 
evidenciada maior prevalência de bacteriúria significativa em pacientes do sexo feminino e na faixa etária dos 61 até os 80 anos. Quanto ao perfil de resistência, observa-se alto índice de resistência de Enterobacter spp., frente aos antimicrobianos, seguida por E. coli e S. aureus.

\section{REFERÊNCIAS}

1. Dias IOV, Coelho ADM, Dorigon I. Infecção do trato urinário em pacientes ambulatoriais: prevalência e perfil de sensibilidade frente aos antimicrobianos no período de 2009 a 2012. Saúde (Santa Maria). 2015;41(1):209-18. https://doi.org/10.5902/2236583415455

2. Camargo ILBC, Maschieto A, Salvino C, Darini ALC. Diagnóstico bacteriológico das infecções do trato urinário-uma revisão técnica. Medicina (Ribeirão Preto). 2001;34:70-8.

3. Pires MCS, Frota KS, Martins Júnior PO, Correa AF, CortezEscalante JJ, Silveira CA. Prevalência e suscetibilidades bacterianas das infecções comunitárias do trato urinário, em Hospital Universitário de Brasília, no período de 2001 a 2005. Rev Soc Bras Med Trop. 2007;40(6):643-7. https://doi.org/10.1590/S003786822007000600009

4. Santana TCFSD, Pereira EDMM, Monteiro SG, Carmo MSD, Turri RDJG, Figueiredo PMS. Prevalência e resistência bacteriana aos agentes antimicrobianos de primeira escolha nas infecções do trato urinário no município de São Luís-MA. Rev Patol Trop. 2012;41(4):409-18. https://doi.org/10.5216/rpt.v41i4.21704

5. Focaccia R. Tratado de infectologia. 4a ed. São Paulo: Atheneu; 2009.

6. Rodrigues CEFB, Costa APF, Sarmento ACA, Queiroz MDLD, Rodrigues MAG, Oliveira RLF. Perfil epidemiológico das infecções urinárias diagnosticadas em pacientes atendidos no Laboratório Escola da Universidade Potiguar, Natal, RN. NewsLab. 2013;119:108-16.

7. Correa I, Camargo LFA. Infecções bacterianas graves: infecções do trato urinário. São Paulo: Lemos Editorial; 2004.

8. Braoios A, Turatti TF, Meredija LCS, Campos TRS, Denadal FHM. Infecções do trato urinário em pacientes não hospitalizados: etiologia e padrão de resistência aos antimicrobianos. J Bras Patol Med Lab. 2009;45(6):449-56. https://doi.org/10.1590/S167624442009000600003

9. Silva JC, Soares MMSR, Gonçalves AS. Estudo retrospectivo de bactérias Gram-negativas isoladas a partir de uroculturas e determinação de seu perfil de resistência. NewsLab. 2014;122:82-90.

10. Lopes V, Tavares W. Diagnóstico das infecções do trato urinário. Rev Assoc Med Bras. 2005;51(6):301-12. https://doi.org/10.1590/ S0104-42302005000600008

11. Dias Neto JA, Silva LDMD, Martins ACP, Tiraboschi RB, Domingos ALA, Suaid HJ, Tucci Júnior ST, Cologna AJ. Prevalence and bacterial susceptibility of hospital acquired urinary tract infection. Acta Cir Bras. 2003;18(Suppl.5):33-8. https://doi.org/10.1590/S010286502003001200012

12. Brasil. Agência Nacional de Vigilância Sanitária. Resolução (RDC) no 20, de 05 de maio de 2011. Dispõe sobre o controle de medicamentos à base de substâncias classificadas como antimicrobianos, de uso sob prescrição, isoladas ou em associação. DOU [Internet]. 2011 Maio 9 [capturado 2016 Jun 5]. Disponível em: www.anvisa.gov.br/sngpc/Documentos2012/RDC\%2020\%202011. pdf?jornal
13. Brasil. Ministério da Saúde. Resolução (RDC) no 466, de 12 de dezembro de 2012. Aprovar as diretrizes e normas regulamentadoras de pesquisas envolvendo seres humanos. DOU [Internet]. 2013 Jun 13 [capturado 2016 Jun 5]. Disponível em: www. conselho.saude. gov.br/resolucoes/2012/Reso466.pdf

14. Poletto KQ, Reis C. Suscetibilidade antimicrobiana de uropatógenos em pacientes ambulatoriais na cidade de Goiânia, GO. Rev Soc Bras Med Trop. 2005;38(5):416-20. https://doi.org/10.1590/S003786822005000500011

15. Muller EV, Santos DF, Corrêa NAB. Prevalência de microrganismos em infecções do trato urinário de pacientes atendidos no laboratório de análises clínicas da Universidade Paranaense - Umuarama-PR. RBAC. 2008;40(1):35-7.

16. Rodrigues FJ, Barroso AP. Etiologia e sensibilidade bacteriana em infecções do tracto urinário. Rev Port Saúde Pública. 2011;29(2):123-31 https://doi.org/10.1016/S0870-9025(11) 70016-5

17. Martins ACP, Suaid HJ. Infecção do trato urinário no idoso. In: Wroclawski ER, Bendhack A, Damião R, Ortiz V, editores. Guia prático de urologia. São Paulo: Segmento; 2003. p. 15-6.

18. Zimmermann MI, Costa CC, Gonçalves CS, Gaspar MDR, Garden CRB. Perfil epidemiológico da infecção no trato urinário. UEPG Ci Biol Saúde. 2009;15(1):33-42. https://doi.org/10.5212/Publ. Biologicas.v.15i2.033042

19. Lo DS, Ragazzi SLB, Gilio AE, Martinez MB. Infecção urinária em menores de 15 anos: etiologia e perfil de sensibilidade antimicrobiana em hospital geral de pediatria. Rev Paul Pediatr. 2010;28(4): 299-303. https://doi.org/10.1590/S0103-05822010000400003

20. Soares LA, Nishi CYM, Wagner HL. Isolamento das bactérias causadoras de infecções urinárias e seu perfil de resistência aos antimicrobianos. Rev Bras Med Fam e Com. 2006;2(6):84-92. https://doi.org/10.5712/rbmfc2(6)29

21. Hinrichsen SL. DIP. Doenças infecciosas e parasitárias. Rio de Janeiro: Guanabara Koogan; 2005.

22. Sales LM, Silva TM. Staphylococcus aureus Meticilina Resistente: um desafio para a saúde pública. Acta Biomed Bras. 2012;3(1): $1-13$.

23. Massoli MCB, Nardi CPPD, Makino LC, Iturrino RPS. Prevalência de infecções urinárias em pacientes atendidos pelo sistema único de saúde e sua suscetibilidade aos antimicrobianos. Medicina (Ribeirão Preto). 2012;45(3):318-21. https://doi.org/10.11606/issn.21767262.v45i3p318-321

24. Koch CR, Ribeiro JC, Schnor OH, Zimmermann BS, Muller FM, D’Agostin J, Machado V, Zhang L. Resistência antimicrobiana dos uropatógenos em pacientes ambulatoriais, 2000-2004. Rev Soc Bras Med Trop. 2008;41(3):277-81. https://doi.org/10.1590/S003786822008000300010

25. Bail L, Ito CAS, Esmerino LA. Infecção do trato urinário: comparação entre perfil de susceptibilidade e a terapia empírica com antimicrobianos. RBAC. 2006;38(1):51-6.

26. Organização Mundial da Saúde. Resistência antimicrobiana [Internet]. [capturado 2016 Jun 5]. Disponível em: www.who.int/ mediacentre/factsheets/fs194/es/

27. Schwarz S, Silley P, Simjee S, Woodford N, Van Duijkeren E, Johson AP, Gasstra W. Editorial: assessing the antimicrobial susceptibility of bacteria obtained from animals. J Antimicrob Chemother. 2010;65(4):601-4. https://doi.org/10.1093/jac/dkq037 